\title{
Correction to: Predictors of survival of very preterm births (born between 23 and 29 weeks' gestation) at a tertiary care center in Karachi, Pakistan: additional multivariate analyses on data from primary cohort
}

\author{
Mohammad Yawar Yakoob* ${ }^{*}$
}

\section{Correction to: BMC Res Notes (2019) 12:620}

https://doi.org/10.1186/s13104-019-4647-8

For better clarity, the author would like to amend the title of the original article [1].

"Predictors of very preterm births (born between 23 and 29 weeks' gestation) at a tertiary care center in Karachi, Pakistan: additional multivariate analyses on data from primary cohort"

should be read as:

"Predictors of survival of very preterm births (born between 23 and 29 weeks' gestation) at a tertiary care center in Karachi, Pakistan: additional multivariate analyses on data from primary cohort".

The corrected title has been included in this Correction article.

Published online: 23 March 2020
Reference

1. Yakoob MY. Predictors of very preterm births (born between 23 and 29 weeks' gestation) at a tertiary care center in Karachi, Pakistan: additional multivariate analyses on data from primary cohort. BMC Res Notes. 2019;12:620. https://doi.org/10.1186/s13104-019-4647-8.

\section{Publisher's Note}

Springer Nature remains neutral with regard to jurisdictional claims in published maps and institutional affiliations. 